\title{
Can vitamin $D$ induce remission in patients with inflammatory bowel disease?
}

\author{
Ricardo de Alvares Goularta , Sandra Maria Barbalho ${ }^{\mathrm{a}, \mathrm{b}, \mathrm{c}}$
}

School of Medicine, University of Marília (UNIMAR); School of Food and Technology of Marilia (FATEC) São Paulo, Brazil Postgraduate Program in Structural and Functional Interactions in Rehabilitation - UNIMAR - Marília - SP, Brazil.

\begin{abstract}
Background The prevalence of vitamin D (VD) deficiency in adults with inflammatory bowel disease (IBD) has been reported to be very high. In adults with ulcerative colitis (UC) it has been estimated to be around 45-50\%, and in the case of Crohn's disease (CD) it ranges from 35-100\%. This systematic review aimed to address the effects of VD in inducing remission in patients with CD and UC.
\end{abstract}

Methods PubMed, Embase, and Cochrane were searched, and PRISMA guidelines were followed. Nine studies with active disease subjects were evaluated; 5 of them investigated patients with UC, 2 studied patients with CD, while 2 studies included patients with both diseases.

Results The studies show that oral daily doses from $1000 \mathrm{IU}$ can raise VD levels above $20 \mathrm{ng} / \mathrm{mL}$ in patients with active CD or UC. Doses close to 50,000 IU per week are sufficient to raise VD levels above $40 \mathrm{ng} / \mathrm{mL}$. Moreover, daily doses from $2000 \mathrm{IU}$ can be related to improvements in the clinical scores of the disease and improvement in patients' quality of life.

Conclusion It is challenging to define the best doses of VD as a therapeutic adjunct to induce remission in IBD patients, as there are biases in the inclusion of studies, since the route of administration of the VD can vary, as well as the doses and the time of use.

Keywords Vitamin D, cholecalciferol, ulcerative colitis, Crohn's disease, inflammatory bowel disease Ann Gastroenterol 2022; 35 (1): 1-10

\section{Introduction}

Ulcerative colitis (UC) and Crohn's disease (CD) are the primary elements of inflammatory bowel disease (IBD). These conditions may be designated as chronic relapsing idiopathic inflammatory processes of the gastrointestinal tract, whose etiology is not entirely understood. Genetic and environmental factors are related to the disruption of the intestinal epithelial

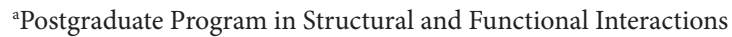
in Rehabilitation - UNIMAR - Marília - São Paulo, Brazil (Ricardo de Alvares Goulart, Sandra Maria Barbalho); 'Department of Biochemistry and Pharmacology, School of Medicine, University of Marília (UNIMAR), Avenida Higino Muzzi Filho, São Paulo, Brazil (Sandra Maria Barbalho); 'School of Food and Technology of Marilia (FATEC), São Paulo, Brazil (Sandra Maria Barbalho)

\section{Conflict of Interest: None}

Correspondence to: Dr. Sandra Maria Barbalho, Department of Biochemistry and Pharmacology, School of Medicine, University of Marília, Av. Higino Muzzi Filho 1001, Marília 15525-902, SP, Brazil, e-mail: smbarbalho@gmail.com

Received 9 April 2021; accepted 15 September 2021; published online 7 January 2022

DOI: https://doi.org/10.20524/aog.2022.0692 barrier, leading to increased permeability and an enhanced uptake of microorganisms that triggers immune system activation. The resulting imbalance may be associated with infections, oxidative stress, high fat and sugar diet, food additives, medications, a decrease in the intake of fibers, and reduced levels of vitamin $\mathrm{D}$ (VD) [1-3].

The world is experiencing an increasing number of patients with IBD, considered as a global burden. Some authors have estimated that more than 1 million people in the United States and 2.5 million in Europe are suffering from this disease. This alarming rise is mainly observed in developed countries, and there is also an increase in the newly industrialized population. People with IBD are affected by abdominal pain symptoms, diarrhea, bleeding, bowel obstruction, extra-intestinal manifestations, and a reduced quality of life (QoL) and capacity for work [4-6].

$\mathrm{VD}$ and its active form 1,25-dihydroxyvitamin $\mathrm{D}$ is defined as a fat-soluble hormone synthesized in skin exposed to sunlight or obtained from the diet. When produced by plants and fungus, it is named ergocalciferol (VD2), and when produced in the skin, it is called cholecalciferol (VD3): 1,25-dihydroxyvitamin D3 1,25(OH)2D3. The active form, $1,25(\mathrm{OH}) 2 \mathrm{D} 3$, is associated with biological effects $[7,8]$.

Besides being associated with the regulation of mineral and bone homeostasis, it modifies adaptive and innate immune 
responses. For these reasons, it has been related to several aspects of inflammation pathways. VD receptors in the thymus and peripheral T-cells are associated with the release of biomarkers of inflammation, such as interleukin (IL)-2 and IL-10 in dendritic cells and macrophages $[9,10]$. VD is related to the upregulation of T regulatory cells, IL-4, IL-10, transforming growing factor- $\beta$, and increased expression of proteins related to cell adhesion, proliferation and migration. On the other hand, it is associated with the downregulation of the expression of tumor necrosis factor (TNF)- $\alpha$, interferon (IFN)- $\gamma$, IL-6, IL-12, the ATG16L1 gene, and lysozyme by Paneth cells. It also reduces bacterial translocation to extra-intestinal tissues, inhibits inflammatory cell infiltrates and reduces colorectal tumors in C57BL/6J and $\mathrm{NOD}^{-/}$-mice $[2,11]$. Intestinal epithelium and mucosal immune cells express the VD receptor. Some studies have shown that this vitamin may regulate the proteins of tight junctions and reduce intestinal apoptosis, thus protecting the gut barrier [12-14]. Fig. 1 summarizes the effects of VD in IBD.
The prevalence of VD deficiency in adults with UC has been estimated at $45-50 \%$ and $35-100 \%$ in CD. This deficiency may be attributed to decreased sunlight exposure, low VD intake, altered enterohepatic circulation, and augmented loss due to enteropathy. In addition, low serum levels of 25-hydroxyvitamin have been reported as a biomarker for disease activity and as a predictive factor for poor clinical outcomes $[15,16]$.

It has not been established whether VD deficiency leads to IBD or vice versa. As shown by Zullow et al [17] in their study of 255 subjects with IBD, most of them had low VD levels, UC was associated with a lower risk of VD insufficiency, and in CD patients VD sufficiency was associated with reduced disease activity and improved QoL.

Although VD has become popular and is considered to aid in the treatment of patients with IBD, few clinical trials have investigated the use of this vitamin in patients with active $\mathrm{UC}$ and CD. More than 20 studies evaluated the use of VD

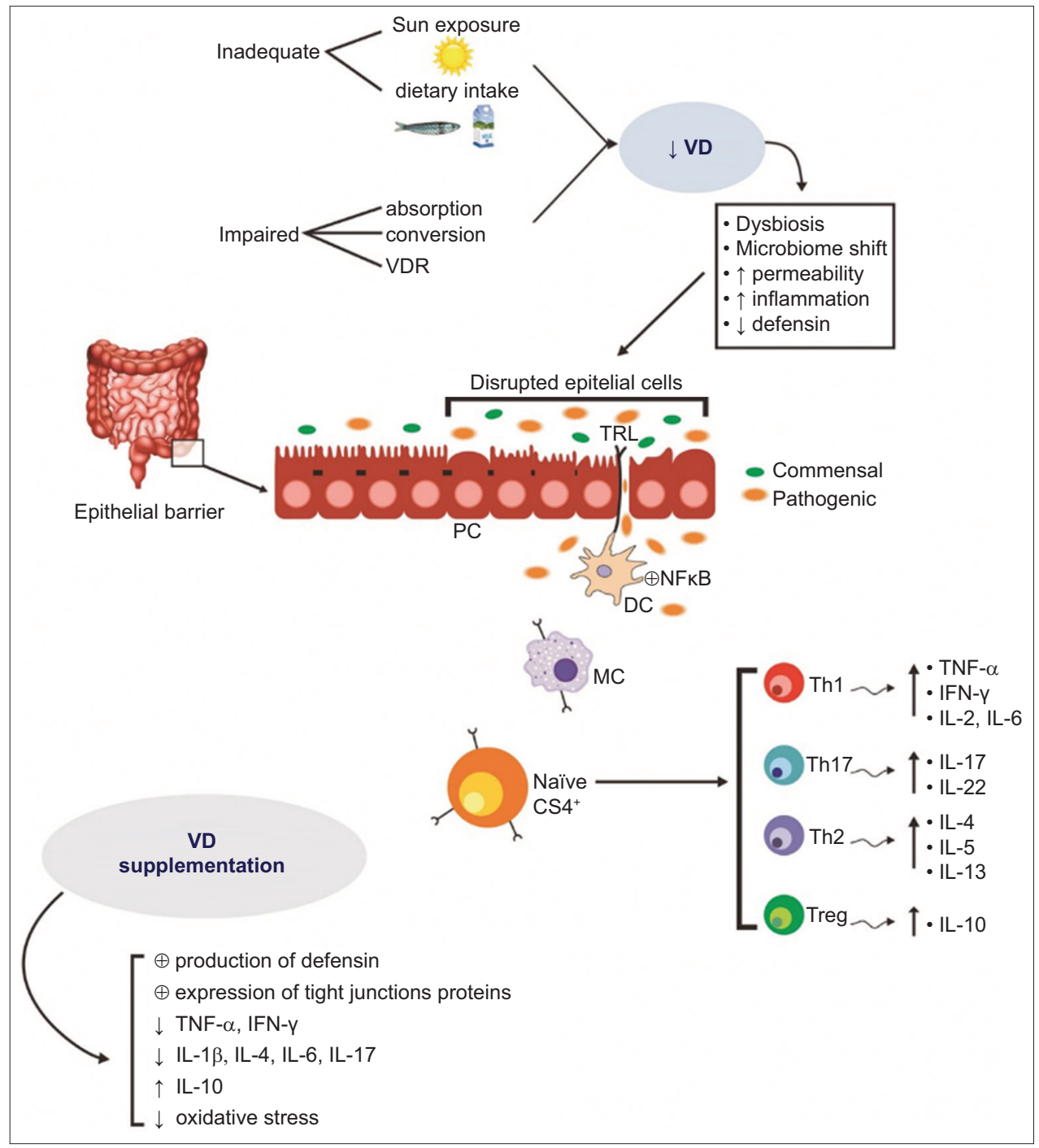

Figure 1 Sources of vitamin D (VD) and its effects on the altered epithelial barrier of patients with inflammatory bowel disease. VD induces immune cells to adopt an anti-inflammatory pattern

IL, interleukin; IFN, interferon; PC, Paneth cell; TH1, Thelper 1; TH2, Thelper 2; TH17, Thelper 17; Treg, regulatory T cells; TNF- $\alpha$, tumor necrosis factor- $\alpha$; VDR, vitamin $D$ receptor 
in patients with IBD, but only 9 included patients with active disease. Therefore, systematic reviews and meta-analyses that consider patients at different stages of the disease may be at risk of significant bias. Since many studies have shown that VD profoundly influences the inflammatory pathways and may help prevent or remission of IBD, this systematic review aimed to evaluate the effects of this vitamin in UC and CD patients in relapse.

\section{Materials and methods}

\section{Focused question}

The focused question used for this review was, "Can vitamin $\mathrm{D}$ assist in the remission of IBD patients?"

\section{Databases}

We searched the MEDLINE/PubMed (National Library of Medicine, National Institutes of Health), Cochrane and EMBASE databases for relevant articles addressing the focused question.

As different terms are used to refer to IBD and VD, the following combinations of $\mathrm{MeSH}$ terms were used: Inflammatory Bowel Disease or Ulcerative Colitis or Crohn's Disease and vitamin D or calcidiol or calcitriol or 25 hydroxycholecalciferol or cholecalciferol. From the resulting list of studies that included these combinations of terms, we selected the articles that investigated the effects of VD in relapsing IBD patients. Two authors evaluated the screening of the studies. This search was not limited to any specific period. We followed the PRISMA (preferred reporting items for a systematic review and meta-analysis) guidelines [18].

\section{Language}

Only studies in English were selected.

\section{Inclusion criteria}

Clinical trails associating the use of VD in patients with active UC and CD were included. We included both full and not full texts available in the consulted databases.

\section{Exclusion criteria}

We excluded studies not in English, reviews, editorials, case reports, studies not involving humans (in animals or in vitro studies), studies with patients in remission, and pediatric cohorts (patients aged less than 18 years).

\section{Eligibility criteria}

Our review's eligibility criteria followed the PICO (population, intervention, comparison, and outcome) format for randomized controlled trials (RCT).

\section{Data extraction}

Two independent judges performed the search for identifying RCT in the databases. The articles' abstracts were evaluated, and full- and no full-text articles were retrieved to support decision-making.

\section{Outcomes}

The outcomes considered were simple clinical colitis activity index (SCCAI), CD activity index (CDAI), IBD questionnaire (IBDQ), Mayo score, short IBDQ (SIBDQ), C-reactive protein (CRP), erythrocyte sedimentation rate (ESR), fecal calprotectin (FC), and QoL. Remission was defined as resolution of visible inflammation and ulceration on endoscopy, a reduction in the Disease Activity Index, and the patient showing cessation of diarrhea, bloating, and pain [19-21].

\section{Quality assessment}

The evaluation of the risk of bias regarding the selection, detection, and reporting bias of each RCT was evaluated according to the Cochrane Handbook for systematic reviews of interventions. Other risks of bias in the selection of patients, classification of interventions, missing data, and measurement of outcomes were also evaluated.

\section{Results}

Fig. 2 shows the selection of the studies. Table 1 summarizes the included RCTs, and Table 2 shows a description of the main biases. All the patients of the included studies maintained the standard drug therapy for IBD during intervention with VD. Nine studies ( 3 from Iran, 1 from India, 1 from Brazil, 1 from China, 1 from Australia, and 2 from the United States) with active disease subjects were included in this systematic review. Five of them were based on patients with UC, 2 with CD, and 2 studies included patients with both diseases. In total, the studies included 387 patients with UC and 124 with CD. The exact number of men and women could not be calculated because 4 studies did not specify the patients' sex.

Although we only included studies with active disease patients, there was a wide variation in the doses administered (daily oral doses of 1000-50,000 IU, 150,000/3 months, or a single injectable dose of 300,000 IU). The treatment duration ranged from 1 day for 300,000 IU [22,23], to 


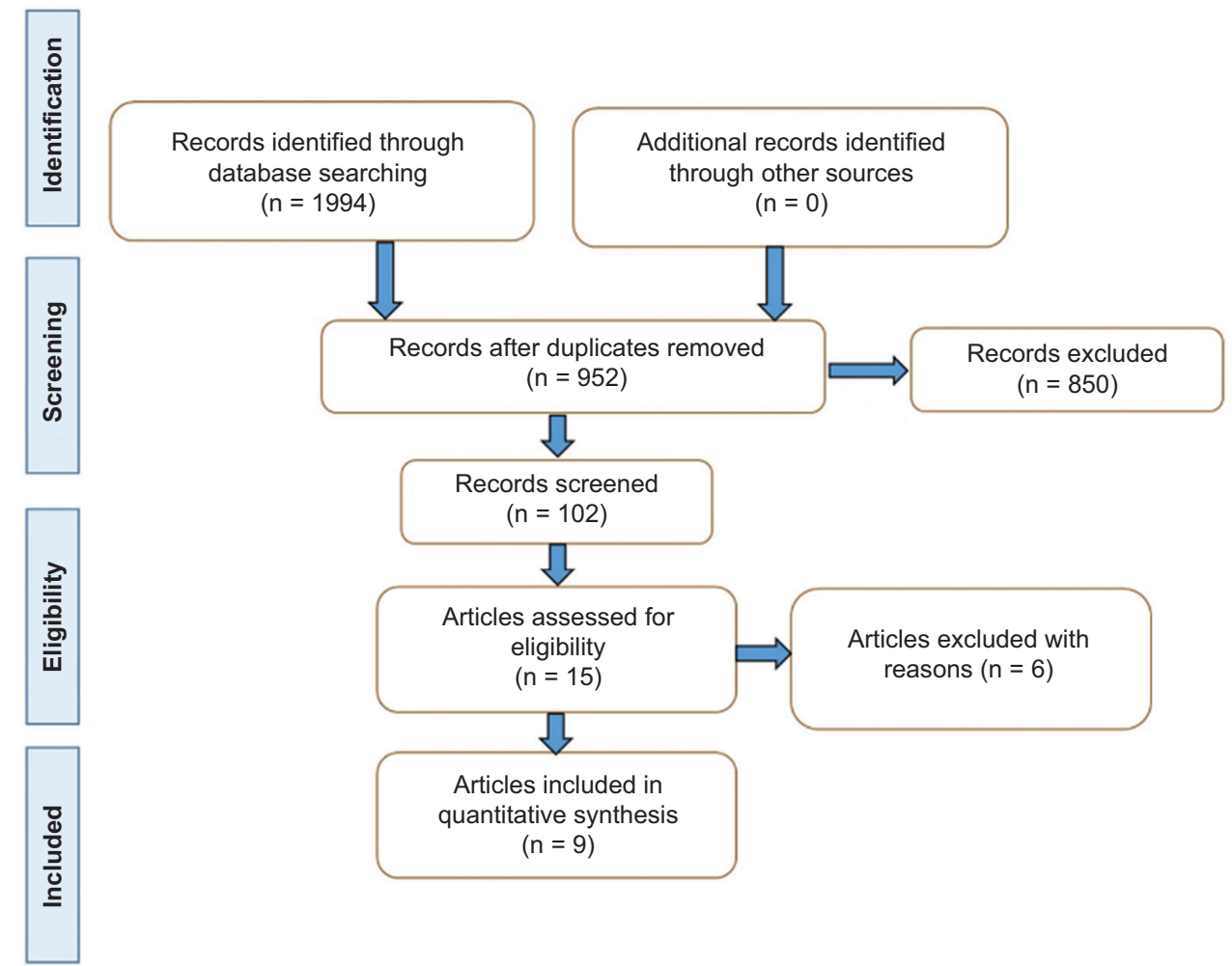

Figure 2 Flow diagram showing the selection of the studies - PRISMA guidelines - [17]

8 days for 60,000 IU [24], and 8 weeks to 1 year for the other doses [25-30].

All studies showed significant improvement in serum VD levels after supplementation (Table 1). The studies of Emani et al [22] and Sharif et al [23], who used a single injectable dose of 300,000 IU, reported a mean level of $40.8 \pm 5.2 \mathrm{ng} / \mathrm{mL}$. Ahamed et al [24] achieved similar values $(40.83 \mathrm{ng} / \mathrm{mL})$ with a daily dose of 60,000 IU/8 days. Even higher values of $46.14 \pm 12.7$ and $45 \pm 19 \mathrm{ng} / \mathrm{mL}$ were obtained by Baffuto et al [28] and Yang et al [29], respectively (although half of the patients included in this last study, who received $5000 \mathrm{IU}$, did not reach values greater than $40 \mathrm{ng} / \mathrm{mL})$. The lowest initial $(10.58 \pm 3.82 \mathrm{in} \mathrm{CD}$ and $10.68 \pm 4.11$ in UC) and final (23.04 \pm 9.66 for CD and $28.09 \pm 11.6$ for UC) VD values were seen in the study of Tan et al [30]. Karimi et al [27] observed the lowest percentage increases in serum VD levels: the group that received 2000 IU presented $21.83 \pm 9.69$ at baseline, and $28.99 \pm 8.69$ after 12 weeks, while the group that received $1000 \mathrm{IU}$ presented $24.37 \pm 8.14$ initally and $28.75 \pm 11.90 \mathrm{ng} / \mathrm{mL}$ after 12 weeks. In the study of Bafutto et al [28], the authors compared supplementation with 2000 (G1), 10,000 (G2), and 50,000 IU (G3)/week and concluded that the highest dose is the best for VD replacement (G1 19.5 \pm 5.1 at baseline and $26 \pm 6.7$ at the end of the study, $\mathrm{P}=0.07$; G2: $19.1 \pm 4.1 / 26 \pm 5.8, \quad \mathrm{P}=0.04$; and $\mathrm{G} 3: 19.5 \pm 6.4 / 46.4 \pm 12.7$, $\mathrm{P}<0.001)$. This study, and the trial performed by Ahamed et al [24] that used 60,000 IU daily for 8 days, showed a higher percentage of augmenting serum levels of VD.

Only 2 studies [24,29] reported remission after VD treatment. Four studies reported an improvement in IBD scores (UCDAI, SCCAI, CDAI) $[24,25,27,29]$ and 4 reported improvements in QoL (IBDQ) [26-29].

One study showed that VD supplementation could suppress the levels of visfatin $(3.1 \pm 1.4$ vs. $1.4 \pm 2.4 \mathrm{ng} / \mathrm{mL} ; \mathrm{P}=0.03)$ and vascular endothelial growth factor (VEGF) $(368 \pm 151$ at baseline and $262 \pm 112$ at the end of the study) in patients with low (insufficiency) of VD [22], suggesting VD might be helpful in reducing proangiogenic factors in UC patients. Nevertheless, the results of this study did not show a significant improvement in visfatin and VEGF at the end of the intervention.

Three studies $[24,26,30]$ observed a significant reduction in CRP (with doses that varied from 2000 IU to 150,000 IU) in UC and CD patients, respectively, whereas others did not see any changes in this marker $[23,25]$.

Only 3 studies investigated the levels of FC, and different results were found. The study of Garg et al [25] did not observe changes in this marker, using 5000 IU of VD daily for 3 months, but the sample had only 10 patients and that may have affected the results. On the other hand, the trial of Ahamed et al [24] showed significant reductions in FC with the use of 6000 IU daily for 8 days in UC patients. Bafutto et al [28] observed a reduction in FC in mild-severe CD patients who received 50,000 IU of VD (but not in those that received 2000 or $10,000 \mathrm{IU}$ ).

Only one [23] of the included studies investigated the levels of IFN- $\gamma$, TNF- $\alpha$, and IL-12p70 and observed significant reductions (respectively, $\mathrm{P}<0.001, \mathrm{P}=0.001$, and $\mathrm{P}=0.001$ ) after an injection of 300,000 IU in UC patients.

Also, only one study [27] investigated the antioxidant/oxidant status of UC patients treated with 1000 or 2000 IU of VD and 


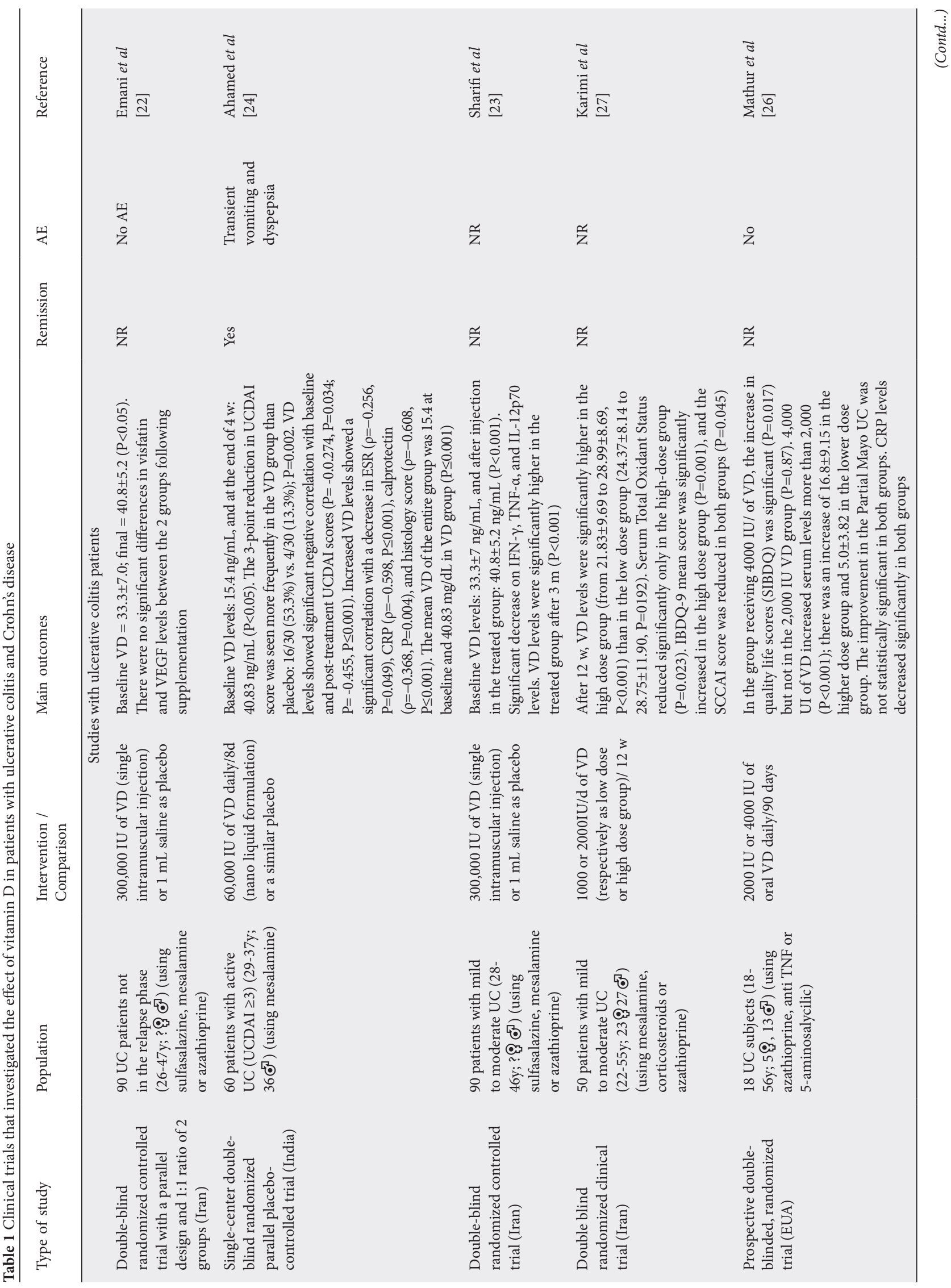




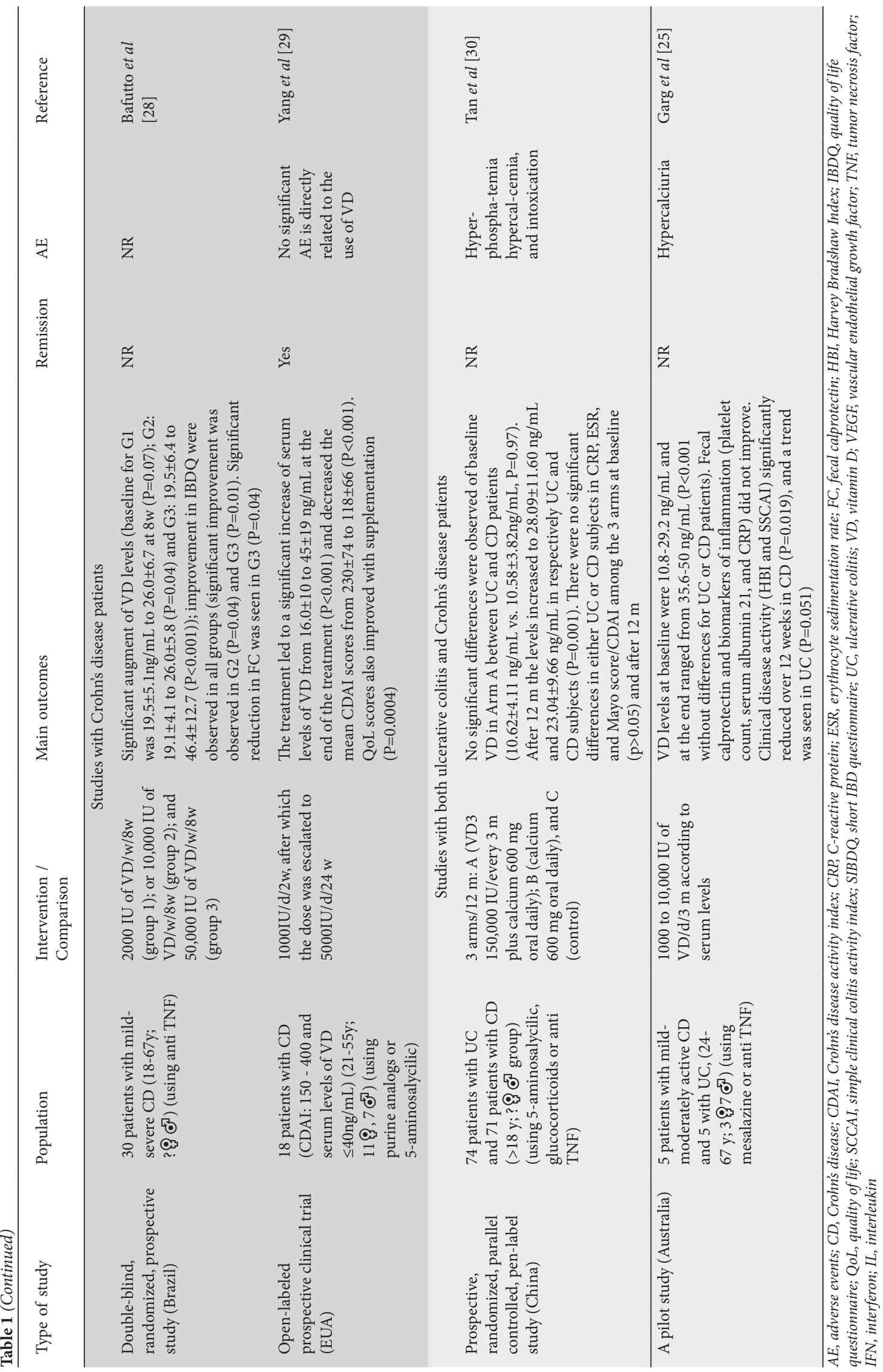


observed a reduction only in total antioxidant status $(\mathrm{P}=0.023)$.

As can be seen in Table 1, 7 of the 9 studies included in this systematic review compared disease activity indexes after using VD ( 3 studies with UC patients, 2 with CD patients, and 2 studies that included both UC and CD subjects). The single-center, double-blinded study of Ahamed et al [24] showed that there was a significant reduction in UCDAI scores after treatment with 60,000 IU of VD daily for 8 days in UC patients compared to the placebo group $(\mathrm{P}=0.001)$. Karimi et al [27] observed a significant reduction in SCCAI score $(\mathrm{P}=0.045)$ in UC patients that received 1000 or 2000 IU daily for 12 weeks, and a significant increase in IBDQ-9 ( $\mathrm{P}=0.001)$ in those patients that received 2000 IU daily. Moreover, Mathur et al [26] used 2000 or 4000 IU daily and observed that UC patients who received the higher dose showed a significant improvement in SIBDQ.

In $\mathrm{CD}$ patients, Bafutto et al [28] observed significant improvement in IBDQ in the groups that received 2000, 10,000 and 50,000 IU for 8 weeks. Yang et al [29] observed a significant reduction in CDAI scores and improved QoL scores in the entire sample that started receiving 1000 daily, with escalation to $5000 \mathrm{IU}$.

Two studies included both UC and CD patients [25,30]. Garg et al [25] observed improvement in clinical disease activity using oral 1000-10,000 IU daily for 3 months. Tan et al [30] did not see significant differences in Mayo score/CDAI in patients who received 150,000 IU every 3 months for a year.

In summary, we can see from the results above that patients with UC achieved improvement in IBDQ-9 with oral doses of VD of $2000 \mathrm{IU}$ (daily/3 months) [27] and improvement in SIBDQ with $4000 \mathrm{IU}$ (daily/3 months) [26]. A significant reduction in UCDAI was observed with use of VD 60,000 IU (daily/8 days) [24]; a reduction in SCCAI with the use of VD 1000-2000 IU (daily/3 months) [27]; and a reduction in SSCAI and HBI (Harvey Bradshaw Index) was seen with the use of VD 1000-10,000 IU (daily/3 months) [25]. Unfortunately, these disease activity scores were not evaluated in the trial with a single intramuscular injection [22]. Furthermore, the results show that, for $\mathrm{CD}$ patients, there was a significant improvement in IBDQ with the daily use of VD 2000, 10,000, and 50,000 IU for 2 months [28]. QoL scores also improved with the dose of 2000 escalated to 5000 IU [29]. The use of 100010,000 IU (daily/3 months) also significantly improved CD patients' clinical disease activity [25].

In the study of Bafutto et al [28], the authors suggest that the dose of 50,000 IU per week is the most appropriate for improving the immunomodulation of $\mathrm{CD}$ patients. However, the immunomodulation was evaluated only by improving FC, which is a potential bias.

\section{Discussion}

Although there is much variation related to the dose (1000-300,000 IU) and form of administration (oral liquid or capsules, or injectable) of VD and the duration of supplementation (1-12 months), the results in patients with active $\mathrm{CD}$ and UC can be promising in inducing remission. However, relevant biases should be considered (Table 2), which can interfere with the studies' results. Indeed, some studies used only a small number of participants [25,26,29]. The studies of Karimi et al [27], Mathur et al [26], Bafutto et al [28], Yang et al [29] and Garg et al [25] did not make comparisons with a placebo group. As previously mentioned, the outcomes assessed were also different.

In addition to clinical trials that included CD or UC patients with active disease, other studies investigated the use of VD in patients in remission. The retrospective cohort study performed by Janssen et al [31] with 384 patients, intended to determine risk factors for VD deficiency, found a high prevalence of CD or UC ( $63 \%$ and $55 \%$, respectively). Their results also showed that VD deficiency is related to disease activity in $\mathrm{CD}$ and to anemia in UC subjects. On the other hand, increasing VD levels correlated with improved CD activity.

Narula et al [32] investigated VD's effects in CD patients in remission. In this randomized and double-blind placebocontrolled trial, the authors evaluated the effects of VD use at $10,000 \mathrm{IU}$ daily compared to $1000 \mathrm{IU}$ for one year and observed significantly higher serum levels in the first group $(\mathrm{P}=0.02)$. Although the relapse rate was not significant in either group, there was an improvement in anxiety and depression scores in both groups treated with vitamin D3.

VD can also affect CD patients as it leads to reduced stimulation of dendritic cells by LPS, explaining the positive effects of VD on CD patients [33]. The open-label pilot study of Wiese et al [34] enrolled CD patients with active disease (CDAI score $>150$ ) treated with 16 oz of IBD nutrition formula (IBDNF) for 4 months. The 28 subjects were consuming regular and similar medications for $\mathrm{CD}$ and were asked to consume $16 \mathrm{oz}$ of IBDNF/day. Nutrition status was assessed, as well as CDAI and IBDQ. The results of this exciting study showed that at the end of 4 months there was a significant increase in the levels of vitamin $\mathrm{D}(25-\mathrm{OH})$ in all patients $(\mathrm{P}<0.001)$. Moreover, the investigators observed a significant reduction in plasma levels of arachidonic acid, augmented eicosapentaenoic and docosahexaenoic acids, and improved QoL in CD subjects.

Jorgensen et al [35] also investigated the effects of VD in a randomized and double-blind placebo-controlled trial in 108 patients with $\mathrm{CD}$ in remission. Subjects were randomized to intake 1200 IU VD $(n=46)$ or placebo $(n=48)$ daily for 12 months and the authors observed that the use of the vitamin increased serum levels from a mean of $69 \mathrm{nmol} / \mathrm{L}$ to $96 \mathrm{nmol} / \mathrm{L}$ after 3 months of treatment $(\mathrm{P}<0.001)$. This paper's exciting results showed that the relapse rate was lower in the treated patients $(\mathrm{P}=0.06)$. In the same clinical trial, Bendix-Struve et al [36] observed that the CD patients who received VD (1200 IU daily) presented higher serum levels of the vitamin and less release of IL-6 compared to the placebo group $(\mathrm{P}<0.02)$. Moreover, VD use increased the proliferating stimulated CD4+ T cells $(\mathrm{P}=0.02)$.

Guzman-Prado et al [15] carried out a systematic review of 19 studies involving the use of VD in patients with either CD or UC. They concluded that supplementation with VD is helpful in improving serum levels; additionally, it is associated with improvement in IBD scores and clinical and biochemical parameters. Although this is a very interesting study, the authors included patients at different stages of the disease, which could have led to bias in the results. 
Table 2 Description of the main biases of the clinical trials that investigated the effects of vitamin D on inflammatory bowel diseases

\begin{tabular}{|c|c|c|c|c|c|c|c|c|c|c|}
\hline Study & $\begin{array}{l}\text { Question } \\
\text { focus }\end{array}$ & $\begin{array}{l}\text { Appropriate } \\
\text { randomization }\end{array}$ & $\begin{array}{l}\text { Allocation } \\
\text { blinded }\end{array}$ & $\begin{array}{l}\text { Double- } \\
\text { blind }\end{array}$ & $\begin{array}{l}\text { Losses } \\
(<20 \%)\end{array}$ & $\begin{array}{l}\text { Prognostics or } \\
\text { demographic } \\
\text { characteristics }\end{array}$ & Outcomes & $\begin{array}{l}\text { Intention } \\
\text { to treat } \\
\text { analysis }\end{array}$ & $\begin{array}{l}\text { Sample } \\
\text { calculation }\end{array}$ & $\begin{array}{l}\text { Adequate } \\
\text { follow } \\
\text { up }\end{array}$ \\
\hline \multicolumn{11}{|c|}{ Ulcerative colitis } \\
\hline $\begin{array}{l}\text { Emani et al } \\
\text { [22] }\end{array}$ & Yes & Yes & Yes & Yes & Yes & $\begin{array}{l}\text { Yes } \\
\text { (incomplete) }\end{array}$ & Yes & Yes & Yes & Yes \\
\hline $\begin{array}{l}\text { Ahamed } \\
\text { et al [24] }\end{array}$ & Yes & Yes & Yes & Yes & Yes & Yes & Yes & Yes & Yes & Yes \\
\hline $\begin{array}{l}\text { Sharifi et al } \\
\text { [23] }\end{array}$ & Yes & Yes & Yes & Yes & Yes & No & Yes & NR & Yes & Yes \\
\hline $\begin{array}{l}\text { Karimi et al } \\
\text { [27] }\end{array}$ & Yes & No & Yes & Yes & Yes & Yes & Yes & Yes & No & Yes \\
\hline $\begin{array}{l}\text { Mathur } \\
\text { et al [26] }\end{array}$ & Yes & Yes & Yes & Yes & Yes & Yes & Yes & No & No & Yes \\
\hline \multicolumn{11}{|c|}{ Crohn's disease } \\
\hline $\begin{array}{l}\text { Bafutto et al } \\
\text { [28] }\end{array}$ & Yes & NR & NR & Yes & No & No & Yes & NR & NR & Yes \\
\hline $\begin{array}{l}\text { Yang et al } \\
\text { [29] }\end{array}$ & Yes & No & No & No & Yes & Yes & Yes & Yes & No & Yes \\
\hline \multicolumn{11}{|c|}{ Crohn's disease and ulcerative colitis } \\
\hline $\begin{array}{l}\text { Tan et al } \\
{[30]}\end{array}$ & Yes & Yes & Yes & No & Yes & No & Yes & No & No & NA \\
\hline $\begin{array}{l}\text { Garg et al } \\
{[25]}\end{array}$ & Yes & No & No & No & Yes & Yes & Yes & Yes & No & Yes \\
\hline
\end{tabular}

NR, Not reported; NA, Not applicable

According to the results of the systematic review performed by Gubatan et al [16], insufficient levels of VD may increase the disease activity among IBD subjects and may be a marker of disease activity. Low VD levels in these patients may occur as a result of malnutrition and malabsorption in flaring patients, or less sun exposure due to poor general wellbeing. Further, low VD status is linked to a higher risk of future clinical relapse. With these considerations, the authors suggest that VD levels may play a cause-and-effect role in the clinical outcomes.

In our review, 5 studies showed flared patients with VD values at baseline lower than $20 \mathrm{ng} / \mathrm{mL}$ [24,25,28-30]. The highest VD levels at baseline were close to $30 \mathrm{mg} / \mathrm{mL}$ in the study of Emani et al [22]. These findings make us wonder if the cutoff value for VD of $20 \mathrm{ng} / \mathrm{mL}$ is sufficient to maintain bone tissue health and maintain or induce remission in IBD patients. Our results, however, indicate that, when patients with low values reach levels above $20 \mathrm{ng} / \mathrm{mL}$, they are already showing improvement in the clinical scores of the disease and in their QoL. Moreover, supplementation with 1000-2000 IU daily is enough to elevate the $20 \mathrm{ng} / \mathrm{mL}$ levels in these patients. On the other hand, our findings show that patients with relapse of the disease always present VD levels lower than $40 \mathrm{ng} / \mathrm{mL}$.

We recommend that VD levels be monitored in IBD patients and that supplements are provided for those deficient in this component. Supplementation should raise levels above $20 \mathrm{ng} /$ $\mathrm{mL}$, which can be achieved with daily doses above $1000 \mathrm{mg} / \mathrm{dL}$. Longer-term administration should be monitored to maintain normal levels of VD and remission of the patients. Another important finding of this review is that the studies show that patients with relapse of the disease never present VD levels above $40 \mathrm{ng} / \mathrm{mL}$. This finding leads us to consider whether patients with IBD should be supplemented with higher doses so their serum levels are not less than $40 \mathrm{ng} / \mathrm{mL}$.

This is the first systematic review that includes only studies performed on relapsed patients to the best of our knowledge. Although our study proposed to use only trials with patients in the same stage of the disease (active disease), we could not eliminate all biases since the doses used and the duration of use of VD was very different. Therefore, we believe it is challenging to define the best doses of this vitamin as a therapeutic adjunct to induce remission in UC and CD patients. Oral daily doses from $1000 \mathrm{IU} / 12$ weeks can raise VD levels above $20 \mathrm{ng} / \mathrm{mL}$ in $\mathrm{UC}$ or $\mathrm{CD}$ patients with active disease, and doses close to $50,000 \mathrm{IU}$ per week are sufficient to raise VD levels above $40 \mathrm{ng} / \mathrm{mL}$. Moreover, doses from 2000 IU per day can be related to improvements in the clinical scores of the disease and improvement in patients' QoL.

\section{References}

1. Mazieiro R, Frizon RR, Barbalho SM, Goulart RA. Is curcumin a possibility to treat inflammatory bowel diseases? J Med Food 


\section{Summary Box}

\section{What is already known:}

- Vitamin D is a modulator of adaptive and innate immune responses

- Vitamin D reduces bacterial translocation to extraintestinal tissues

- Vitamin D is associated with the downregulation of tumor necrosis factor- $\alpha$, interleukins -6 and -12 , thereby offering benefit to patients with inflammatory bowel disease

\section{What the new findings are:}

- The effects of vitamin D on the remission of inflammatory conditions such as ulcerative colitis and Crohn's disease are still somewhat obscure

- The use of vitamin D in flared patients can interfere with remission

- The dosages of vitamin D can influence the outcomes

2018;21:1077-1085.

2. Barbalho SM, Goulart RA, Gasparini RG. Associations between inflammatory bowel diseases and vitamin D. Crit Rev Food Sci Nutr 2019;59:1347-1356.

3. Buffet-Bataillon S, Landreau C, Siproudhis L, Cattoir V, Bouguen GJC, Hepatology R.i.; Gastroenterology. Bacterial gut dysbiosis is associated with Crohn's disease symptoms but not with elevated fecal calprotectin. Clin Res Hepatol Gastroenterol 2021;45:101669.

4. Barbalho SM, Bosso H, Salzedas-Pescinini LM, de Alvares Goulart R. Green tea: a possibility in the therapeutic approach of inflammatory bowel diseases?: Green tea and inflammatory bowel diseases. Complement Ther Med 2019;43:148-153.

5. Ng SC, Shi HY, Hamidi N, et al. Worldwide incidence and prevalence of inflammatory bowel disease in the $21^{\text {st }}$ century: a systematic review of population-based studies. Lancet 2017;390:2769-2778.

6. Kaplan GG. The global burden of IBD: from 2015 to 2025. Nat Rev Gastroenterol Hepatol 2015;12:720-727.

7. Rasouli E, Sadeghi N, Parsi A, Hashemi SJ, Nayebi M, Shayesteh A. Relationship between vitamin $\mathrm{D}$ deficiency and disease activity in patients with inflammatory bowel disease in Ahvaz, Iran. Clin Exp Gastroenterol 2020;13:419-425.

8. Alhassan Mohammed $\mathrm{H}$, Mirshafiey A, Vahedi $\mathrm{H}$, et al. Immunoregulation of inflammatory and inhibitory cytokines by vitamin D3 in patients with inflammatory bowel diseases. Scand J Immunol 2017;85:386-394.

9. Szymczak-Tomczak A, Kaczmarek-Ryś M, Hryhorowicz S, et al. Vitamin D, vitamin D receptor (VDR) gene polymorphisms (ApaI and FokI), and bone mineral density in patients with inflammatory bowel disease. J Clin Densitom 2021;24:233-242.

10. Shirwaikar Thomas A, Criss ZK, Shroyer NF, Abraham BP. Vitamin D receptor gene single nucleotide polymorphisms and association with vitamin D levels and endoscopic disease activity in inflammatory bowel disease patients: a pilot study. Inflamm Bowel Dis 2021;27:1263-1269.

11. Barbalho SM, Bechara MD, de Alvares Goulart R, et al. Reflections about inflammatory bowel disease and vitamins A and D. J Med Food 2016;19:1105-1110.

12. Del Pinto R, Ferri C, Cominelli F. Vitamin D axis in inflammatory bowel diseases: role, current uses and future perspectives. Int $\mathrm{J} \mathrm{Mol}$ Sci 2017; 18.

13. Dankers W, Colin EM, van Hamburg JP, Lubberts E. Vitamin D in autoimmunity: molecular mechanisms and therapeutic potential. Front Immunol 2016;7:697.

14. Lee PC, Hsieh YC, Huo TI, et al. Active vitamin D(3) treatment attenuated bacterial translocation via improving intestinal barriers in cirrhotic rats. Mol Nutr Food Res 2021;65:e2000937.

15. Guzman-Prado Y, Samson O, Segal JP, Limdi JK, Hayee B. Vitamin $D$ therapy in adults with inflammatory bowel disease: a systematic review and meta-analysis. Inflamm Bowel Dis 2020;26:1819-1830.

16. Gubatan J, Chou ND, Nielsen OH, Moss AC. Systematic review with meta-analysis: association of vitamin $\mathrm{D}$ status with clinical outcomes in adult patients with inflammatory bowel disease. Aliment Pharmacol Ther 2019;50:1146-1158.

17. Zullow S, Jambaulikar G, Rustgi A, Quezada S, Cross RK. Risk factors for vitamin D deficiency and impact of repletion in a tertiary care inflammatory bowel disease population. Dig Dis Sci 2017;62:2072-2078.

18. Moher D, Liberati A, Tetzlaff J, Altman DG; PRISMA Group. Preferred reporting items for systematic reviews and metaanalyses: the PRISMA statement. Ann Intern Med 2009;151:264269, W64.

19. Bryant R, Winer S, SPL T, Riddell RJJC Colitis. Systematic review: histological remission in inflammatory bowel disease. Is 'complete' remission the new treatment paradigm? An IOIBD initiative. J Crohns Colitis 2014;8:1582-1597.

20. Zallot C, Peyrin-Biroulet LJC. Deep remission in inflammatory bowel disease: looking beyond symptoms. Curr Gastroenterol Rep 2013; 15:315.

21. Limketkai BN, Iheozor-Ejiofor Z, Gjuladin-Hellon T, et al. Dietary interventions for induction and maintenance of remission in inflammatory bowel disease. Cochrane Database Syst Rev 2019;2:CD012839.

22. Emami MR, Sharifi A, Yaseri M, Derakhshanian H, HosseinzadehAttar MJ. Vitamin D suppresses proangiogenic factors in patients with ulcerative colitis: a randomized double blind placebo controlled clinical trial. Complement Ther Clin Pract 2020;39:101086.

23. Sharifi A, Vahedi H, Nedjat S, Rafiei H, Hosseinzadeh-Attar MJ. Effect of single-dose injection of vitamin D on immune cytokines in ulcerative colitis patients: a randomized placebo-controlled trial. APMIS 2019;127:681-687.

24. Ahamed Z R, Dutta U, Sharma V, et al. Oral nano vitamin D supplementation reduces disease activity in ulcerative colitis: a double-blind randomized parallel group placebo-controlled trial. J Clin Gastroenterol;53:e409-e415.

25. Garg M, Rosella O, Rosella G, Wu Y, Lubel JS, Gibson PR. Evaluation of a 12-week targeted vitamin D supplementation regimen in patients with active inflammatory bowel disease. Clin Nutr 2018;37:1375-1382.

26. Mathur J, Naing S, Mills P, Limsui D. A randomized clinical trial of vitamin $\mathrm{D}(3)$ (cholecalciferol) in ulcerative colitis patients with hypovitaminosis D(3). PeerJ 2017;5:e3654.

27. Karimi S, Tabataba-Vakili S, Yari Z, et al. The effects of two vitamin $\mathrm{D}$ regimens on ulcerative colitis activity index, quality of life and oxidant/anti-oxidant status. Nutr J 2019;18:16.

28. Bafutto M, Oliveira E, Costa M, et al. P-112 evaluation of vitamin $\mathrm{D}$ supplementation in moderate to severe Crohn's disease patients using anti-TNF: replacement or immunomodulation? Inflamm Bowel Dis 2017;23:S40.

29. Yang L, Weaver V, Smith JP, Bingaman S, Hartman TJ, Cantorna MT. Therapeutic effect of vitamin $\mathrm{d}$ supplementation in a pilot study of 
Crohn's patients. Clin Transl Gastroenterol 2013;4:e33.

30. Tan B, Li P, Lv H, et al. Treatment of vitamin D deficiency in Chinese inflammatory bowel disease patients: a prospective, randomized, open-label, pilot study. J Dig Dis 2018;19:215-224.

31. Janssen CE, Globig AM, Busse Grawitz A, Bettinger D, Hasselblatt P. Seasonal variability of vitamin D status in patients with inflammatory bowel disease - a retrospective cohort study. PLoS One 2019;14:e217238.

32. Narula N, Cooray M, Anglin R, Muqtadir Z, Narula A, Marshall JK. Impact of high-dose vitamin D3 supplementation in patients with Crohn's disease in remission: a pilot randomized double-blind controlled study. Dig Dis Sci 2017;62:448-455.

33. Bartels LE, Bendix M, Hvas CL, et al. Oral vitamin D3 supplementation reduces monocyte-derived dendritic cell maturation and cytokine production in Crohn's disease patients. Inflammopharmacology 2014;22:95-103.

34. Wiese DM, Lashner BA, Lerner E, DeMichele SJ, Seidner DL. The effects of an oral supplement enriched with fish oil, prebiotics, and antioxidants on nutrition status in Crohn's disease patients. Nutr Clin Pract 2011;26:463-473.

35. Jørgensen SP, Agnholt J, Glerup H, et al. Clinical trial: vitamin D3 treatment in Crohn's disease - a randomized double-blind placebocontrolled study. Aliment Pharmacol Ther 2010;32:377-383.

36. Bendix-Struve M, Bartels LE, Agnholt J, Dige A, Jørgensen SP, Dahlerup JF. Vitamin D3 treatment of Crohn's disease patients increases stimulated T cell IL-6 production and proliferation. Aliment Pharmacol Ther 2010;32:1364-1372. 